\title{
Short-term effects of femtosecond laser assisted cataract surgery (FLACS) on central and peripheral cornea thickness
}

\author{
Milena Pahlitzsch ${ }^{*}$, Marie Luise Pahlitzsch ${ }^{2}$ and Thomas Pahlitzsch ${ }^{3}$ \\ ${ }^{1}$ UCL Institute of Ophthalmology, 11-43 Bath Street, London EC1V 9EL, UK \\ ${ }^{2}$ University clinic Frankfurt/Main, Institute of Ophthalmology, Theodor-Stern-Kai 7, 60590 Frankfurt am Main, Germany \\ ${ }^{3}$ Eye clinic Wittenbergplatz, Kleiststr. 23-26, 10787 Berlin, Germany
}

\begin{abstract}
Background: To assess the alterations of the cornea thickness following femtosecond laser assisted cataract surgery (FLACS) compared to the manual phacoemulsification.

Methods: Data of $n=42$ FLACS (66.2 years) and $n=40$ manual phacoemulsification ( 71.3 years) were analysed. The procedures were performed by LenSx Alcon and Alcon Infiniti Vision System, USA. The laser setting for performing the anterior capsulotomy (diameter $5 \mathrm{~mm}$ ) was $4.8 \mu \mathrm{J}$ and $8.9 \mu \mathrm{J}$ for the nucleus. Following parameters were examined; corneal thickness (Pentacam, Oculus Inc., Germany) at intervals of $0.4 \mathrm{~mm}$ to the peripheral 8 mm zone, anterior chamber depth, intraocular pressure and number of endothelial cells (NIDEK CoLtd, Japan). The analysis was performed preoperatively, directly post femtosecond laser treatment (within $15 \mathrm{~min}$ ) and 1 day post-surgery.

Results: A significant difference was not observed in the central and peripheral corneal thickness at any location ( $p>0.05$ ) in FLACS compared to manual Phaco. As a trend, the complete FLACS cohort showed an increase in the peripheral corneal thickness between 4-8 mm at 1 day postoperative. The peripheral cornea thickness was significantly increased in the female FLACS cohort (4-8 mm, p<0.05). Analysing FLACS and manual Phaco considering the AC depth range of 2.5-3.5 mm could not show significant differences between the two cohorts $(\mathrm{p}>0.05)$.

Conclusions: The results of this study suggest that conventional laser energy levels did not have a harmful short-term impact on the cornea.
\end{abstract}

Abbreviations: FLACS: Femtosecond Laser Assisted Cataract Surgery, LOCS: Lens Opacities Classification System, IOP: Intraocular Pressure

\section{Background}

Femtosecond laser systems operate at near-infrared (near-IR) wavelengths ranging from 1030 to $1064 \mathrm{~nm}$ [1-5]. Accordingly, thelinear absorption and scattering is relatively low in water and nonpigmented tissues such as the cornea, aqueous humor, lens, and vitreous. Thus, the laser light passes through the anterior segment with little effect until it is focused on the lens [6]. The amount of this little effect is not exactly known on human tissue. Additionally, Kohnen et al. [7] stated the importance of different pulse energy levels on the tissue outcome. Studies relating to femtosecond laser assisted cataract surgery (FLACS) evaluated the phacoemulsification time, the intraocular lens placement, the capsule overlap, the circularity of capsulotomy, the centration of the intraocular lens and the central cornea thickness in order to assess advances and perioperative complications compared to the standard cataract surgery $[1-5,8]$. To date they did not analyse the impact on the cornea at $0.4 \mathrm{~mm}$ intervals due to the laser energy [1-3]. We wanted to assess the clinical impact of the laser energy by the femtosecond laser across the cornea. We assumed that the laser energy was applied to the lens on a widespread plane, whereas the ultrasound energy was more centrally and ideally deep-seated applied during phacoemulsification. Relating to the manual procedure the cornea, especially the endothelial cells, were protected by the viscoelastic substance in the anterior chamber, which partly absorbed the ultrasound energy and reduced damage of reactive oxygen species [9-13]. In contrast, during the laser application the endothelial cells were fully exposed to the laser energy as the laser beam easily goes through the aqueous humour [6]. Laser energy can cause damage using three mechanisms: 1 . microbubble formation from vaporization [14], 2. mechanical shock-wave damage from confined overheating of melanosomes during a single pulse, and 3. cumulative thermal damage from prolonged heating of the RPE and choroid $[15,16]$.

Highlighting specific characteristics of the cornea, it was known that the central corneal thickness was directly correlated with refraction $(p=0.028)$ and inversely with age $(p=0.027)$ [16]. Hashemi et al. [17] found in a population-based study, that the thinnest point was usually located inferotemporally and the thickest point superiorly. The peripheral cornea was significantly thicker than the central cornea but tapered faster with age [17]. Recent modalities such as Pentacam, Orbscan, and AC-Master showed a high agreement with few outliers when comparing cornea thickness and anterior chamber depth values $[18,19]$. A single Pentacam scan will be sufficient for most clinical applications [18]. Following comparative data this method was used in our study to measure the corneal thickness.

The main goal of this study was to evaluate if there were significant structural changes in cornea thickness due to back scattered radiation

Correspondence to: Dr. med. Milena Pahlitzsch, UCL Institute of Ophthalmology, 11-43 Bath Street, London EC1V 9EL, England, Tel: +491721537002; Fax: +49307748876; E-mail: milena.pahlitzsch@charite.de

Key words: cornea thickness, femtosecond laser assisted cataract surgery, pachymetry, phacoemulsification

Received: February 03, 2017; Accepted: February 17, 2017; Published: February 20, 2017 
in FLACS compared to the manual phaco control.

\section{Methods}

Data of 82 eyes $(n=82)$ were included in this prospective study from May 2015 to November 2015, following the Declaration of Helsinki. The study cohort was split in two groups: $n=42$ FLACS (mean age 66.2 years, 23 male, 19 female) and $n=40$ manual Phacoemulsification (mean age 71.3 years, 15 male, 25 female). Informed written patient consent was obtained prior to surgery.

For each patient an ophthalmologic examination with medical history, best-corrected visual acuity, slit lamp examination and fundoscopy was performed. In this study design the following characteristics were observed: The corneal thickness (Oculus Pentacam, Oculus Inc.,Wetzlar, Germany) at $0.4 \mathrm{~mm}$ intervals in order of the concentric circles of the Scheimpflug, intraocular pressure, the anterior chamber depth and the number of endothelial cells (specular microscope, CEM-530 NIDEK Co. Ltd, Japan).

All data were conducted preoperatively, immediately post femtosecond laser (within $15 \mathrm{~min}$ ) and 1 day post-surgery. No patient drop out was registered. The intraocular lens calculation was provided by the IOL Master using the SRK/T formula (Zeiss, Meditec AG). The Pentacam Scheimpflug densitometric method, with the blue lightscattering intensity of the lens layers numerically graded, was used to measure the nuclear density in the Lens Opacities Classification System (LOCS) $[20,21]$.

Inclusion criteria were the nuclear density score LOCS II, no other surgery $<3$ months, clear cornea and a systemic disease in a stable condition (diabetes Hbalc maximum 7\%, controlled hypertensive blood pressure). Exclusion criteria were LOCS I, III, IV, astigmatism $>1$ diopter, spherical error $>3$ diopter, intraocular pressure $>22 \mathrm{mmHg}$, uncontrolled systemic disease (diabetes, hypertensive blood pressure), autoimmune disease, uveitis, keratitis, corneal scarring and hazy optic media. Co-existing eye comorbidities including any kind of topical therapy prior to surgery and on a regular base were excluded.

One subgroup including the AC depth of 2.5-3.5 mm ( $\mathrm{n}=22$ FLACS, $\mathrm{n}=25$ Phaco control) was analysed. The criterion of this subgroup was chosen considering the total number of patients included in this study. Intraocular pressure was measured by the ICare tonometry (Tiolat, Helsinki, Finland) preoperatively, post femtosecond laser procedure (within $15 \mathrm{~min}$ ) and 1 day post-surgery.

\section{Surgery technique}

The femtosecond laser procedures were performed using the LenSx laser (Alcon Laboratories Inc., Fort Worth, TX, USA) under topical anaesthesia with Conjucain EDO (oxybuprocainhydrochloride, 4.0 $\mathrm{mg} / \mathrm{ml}$, Dr. Mann Pharma GmbH, Berlin, Germany) by the same surgeon (TP). The LenSx laser is a $50 \mathrm{kHz}$ femtosecond infrared laser with a pulse width of 600-800 femtoseconds, a central laser wavelength of $1.030 \mathrm{~nm}$ and maximum pulse energy of $15 \mu \mathrm{J}$. The laser pulse energy setting for performing the anterior capsulotomy was $4.8 \mu \mathrm{J}$ and $8.9 \mu \mathrm{J}$ for the nucleus (Offset up $200 \mathrm{um}$, down $250 \mathrm{um}$ ). The depth and coordinates of the capsulotomies were determined by the laser system's optical coherence tomography (OCT). The diameter of the capsulotomy was set to $5 \mathrm{~mm}$.

The interface was built as an extended suction skirt and an additional soft contact lens between the applanation lens and the cornea, which allowed a decrease of laser pulse energy while maintaining the ability to perform capsulotomies. After docking was performed, the cornea was applanated and suction was activated. After laser treatment, undocking was performed and the interface with the contact lens was removed. Phacoemulsification was performed with the Alcon Infiniti Vision System. The bottle height was set at $110 \mathrm{~cm} \mathrm{H}_{2} \mathrm{O}$ in all surgeries. No corneal incisions were made by the femtosecond laser during this study. The clear cornea incisions, manually cut by one surgeon, were closed by delicate stromal hydration in FLACS and manual phacoemulsification; the temporal access for intraocular lens implantation was chosen for all eyes ( 9 o'clock for the right eye, 3 o'clock for the left eye).

Postoperative treatment just started after the examinations were conducted 1 day postoperative. The schedule was comprised of a topical combination of steroids and antibiotics that were reduced over four weeks following the intervention.

\section{Oculus Pentacam}

Oculus Pentacam (Oculus Inc.,Wetzlar, Germany) images were obtained under pupil dilatation with $1 \%$ tropicamide. To reduce operator-dependent variables, Pentacam's automatic release mode was used. In this mode, the instrument automatically determined when correct focus and alignment with the corneal apex was achieved and then performed a scan. In less than 2 seconds, the rotating camera captured up to 50 slit images of the anterior segment [20].

\section{Statistical analysis}

Statistical data were calculated using Statistical Package for the Social Sciences (SPSS, IBM) version 20.0. For randomization, a software programm (Stata version 11; Stata Corp., College Station, TX) was used with a 1:1 ratio. After primary assessment of participants, individuals were allocated to each surgery arm using the sequence of the randomization table by a third person. Linear regression analysis and descriptive statistics (mean, standard deviation, 95\% limits of agreement) were processed. A p-value of less than 0.05 indicated a statistically significant difference. Preoperative and postoperative values were compared with the dependent sample t-test. Numeric variables that were not normally distributed, were compared with the Mann-Whitney $U$ test. To correct for multiple testing results were adjusted by the Bonferroni-Holm method. The Wilcoxon Test was used for comparing two related samples or repeated measurements on a single sample.

\section{Results}

Data of $n=82$ patients were analysed. Distribution of surgery eyes resulted in following data; 20 left and 22 right eyes in FLACS and 19 left and 21 right eyes in the manual phaco group. The mean AC Depth was $2.73 \pm 0.50 \mathrm{~mm}$ in FLACS and $3.07 \pm 0.84 \mathrm{~mm}$ in the manual phaco cohort preoperatively $(\mathrm{p}=0.058)$. A mean reduction of ultrasound energy by $31.4 \%$ was assessed in the FLACS cohort compared to the phaco control. The mean number of endothelial cells was preoperatively $2.594 / \mathrm{mm}^{2}$ in FLACS and $2.636 / \mathrm{mm}^{2}$ in the phaco control and was reduced to $2.489 / \mathrm{mm}^{2}$ and $2.527 / \mathrm{mm}^{2}$ in FLACS and phaco control 1 day postoperative $(\mathrm{p}>0.05)$. There was no significant difference of endothelial cells between both surgical procedures at 1 day postoperatively $(\mathrm{p}>0.05)$. The intraocular pressure was preoperatively $19.5 \pm 0.8 \mathrm{mmHg}$ and $18.1 \pm 1.1 \mathrm{mmHg}$ in the FLACS and phaco control $(\mathrm{p}=0.127), 17.1 \pm 1.5 \mathrm{mmHg} 15 \mathrm{~min}$ post femtosecond laser procedure in the FLACS cohort and $18.9 \pm 2.1 \mathrm{mmHg}$ in the FLACS and $18.7 \pm 2.6$ $\mathrm{mmHg}$ in the phaco control group at 1 day postoperatively $(\mathrm{p}=0.145)$. Between FLACS and the phaco control there was no significant difference at all peripheral cornea intervals ( $\mathrm{p}>0.05$, Table 1$)$. 
Table 1. P-value of the cornea thickness between the Femtosecond laser assisted cataract surgery (FLACS) and the manual Phacoemulsification cohort in the complete study cohort and in one subgroup including the AC depth range of $2.5-3.5 \mathrm{~mm}$ according to the Pentacam concentric rings at $0.4 \mathrm{~mm}$ intervals.

\begin{tabular}{|c|c|c|c|c|c|c|}
\hline & \multicolumn{5}{|c|}{ Distance from central cornea } \\
\hline $\begin{array}{c}\text { Total } \\
\text { cohort }\end{array}$ & $\mathbf{0 . 0} \mathbf{~ m m}$ & $\mathbf{0 . 4} \mathbf{~ m m}$ & $\mathbf{0 . 8} \mathbf{~ m m}$ & $\mathbf{1 . 2} \mathbf{~ m m}$ & $\mathbf{1 . 6} \mathbf{~ m m}$ & $\mathbf{2 . 0} \mathbf{~ m m}$ \\
\hline p value & 0.227 & 0.2 & 0.232 & 0.24 & 0.245 & 0.275 \\
\hline & $\mathbf{2 . 4} \mathbf{~ m m}$ & $\mathbf{2 . 8} \mathbf{~ m m}$ & $\mathbf{3 . 2} \mathbf{~ m m}$ & $\mathbf{3 . 6} \mathbf{~ m m}$ & $\mathbf{4 . 0} \mathbf{~ m m}$ & $\mathbf{4 . 4} \mathbf{~ m m}$ \\
\hline p value & 0.294 & 0.312 & 0.351 & 0.377 & 0.421 & 0.46 \\
\hline & $\mathbf{4 . 8} \mathbf{~ m m}$ & $\mathbf{5 . 2} \mathbf{~ m m}$ & $\mathbf{5 . 6} \mathbf{~ m m}$ & $\mathbf{6 . 0} \mathbf{~ m m}$ & $\mathbf{6 . 4} \mathbf{~ m m}$ & $\mathbf{6 . 8} \mathbf{~ m m}$ \\
\hline p value & 0.536 & 0.576 & 0.646 & 0.716 & 0.777 & 0.755 \\
\hline & $\mathbf{7 . 2} \mathbf{~ m m}$ & $\mathbf{7 . 6} \mathbf{~ m m}$ & $\mathbf{8 . 0} \mathbf{~ m m}$ & & & \\
\hline p value & 0.763 & 0.732 & 0.931 & & & \\
\hline $\begin{array}{c}\text { AC depth } \\
\mathbf{2 . 5 - 3 . 5 m m}\end{array}$ & $\mathbf{0 . 0} \mathbf{~ m m}$ & $\mathbf{0 . 4} \mathbf{~ m m}$ & $\mathbf{0 . 8} \mathbf{~ m m}$ & $\mathbf{1 . 2} \mathbf{~ m m}$ & $\mathbf{1 . 6} \mathbf{~ m m}$ & $\mathbf{2 . 0} \mathbf{~ m m}$ \\
\hline p value & 0.630 & 0.600 & 0.672 & 0.674 & 0.695 & 0.729 \\
\hline & $\mathbf{2 . 4} \mathbf{~ m m}$ & $\mathbf{2 . 8} \mathbf{~ m m}$ & $\mathbf{3 . 2} \mathbf{~ m m}$ & $\mathbf{3 . 6} \mathbf{~ m m}$ & $\mathbf{4 . 0} \mathbf{~ m m}$ & $\mathbf{4 . 4} \mathbf{~ m m}$ \\
\hline p value & 0.806 & 0.854 & 0.886 & 0.928 & 0.967 & 0.974 \\
\hline & $\mathbf{4 . 8} \mathbf{~ m m}$ & $\mathbf{5 . 2} \mathbf{~ m m}$ & $\mathbf{5 . 6} \mathbf{~ m m}$ & $\mathbf{6 . 0} \mathbf{~ m m}$ & $\mathbf{6 . 4} \mathbf{~ m m}$ & $\mathbf{6 . 8} \mathbf{~ m m}$ \\
\hline p value & 0.912 & 0.918 & 0.900 & 0.896 & 0.905 & 0.978 \\
\hline & $\mathbf{7 . 2} \mathbf{~ m m}$ & $\mathbf{7 . 6} \mathbf{~ m m}$ & $\mathbf{8 . 0} \mathbf{~ m m}$ & & & \\
\hline p value & 0.977 & 0.982 & 0.988 & & & \\
\hline & & & & & & \\
\hline
\end{tabular}

In Figure 1-3, the pre-and post-treatment values of the cornea thickness were graphically presented using the box plot analysis. Spliting the cohorts in female and male subjects, the peripheral cornea thickness was significantly increased in the female FLACS cohort (4-8 $\mathrm{mm}, \mathrm{p}<0.05$ ) according to the concentric circles of the Pentacam (Figure 4). There was no significant correlation between male and female in the complete phaco control ( $p>0.05$, Figure 4$)$. The same results were raised in both surgical procedures in the cohort considering only individuals with an AC depth of 2.5-3.5 mm. Additionally, analysing FLACS and phaco control considering the AC depth range of 2.5-3.5 mm could not show significant differences between the two cohorts $(\mathrm{p}>0.05$, Figure 5, Table 1).

\section{Discussion}

During the femtosecond laser treatment the eye ball is fixed and the intraocular pressure rises for that short period of time. This IOP increase could impede or prevent blood flow in the retina and choroid, which is an important variable affecting the thermal damage threshold [6]. The reduced cooling by the blood flow could lead to increased intraocular temperatures [6]. Sun et al. [22] stated, however, that the cumulative thermal damage did not present a safety hazard on the anterior eye in porcine cadaver. According to the retinal safety, FLACS had an additional important factor that arises from plasma absorption and bubble scattering, which significantly decreased the fraction of laser power reaching the retina under the laser beam [6].

Can this positive effect of the bubbles relating to the retina harm the cornea? Will the laser beams be reflected on the bubbles and thus increase the laser energy in the anterior eye? Chatoux et al. [23] assessed the coalescent bubbles created by plasma formation and the results showed that the bubbles always disappeared in less than $24 \mathrm{~h}$. The non-thermal effect of plasma on surrounding tissues was proven to be innocuous by the transmission electron microscopy result [23]. Experimental in vivo studies, however, were still necessary in order to define the applications and limits of the cavitation bubbles' kinetics and transfer [23]. It is not exactly known where the laser rays vanish, although comparative studies could not demonstrate a relevant clinical impact on the anterior segment of the eye and the retina $[6,20]$.
In line with a recent study by Yağcl et al. [24], we could not find a significant difference in the central and peripheral cornea thickness at $0.4 \mathrm{~mm}$ intervals between both study cohorts $(\mathrm{p}>0.05)$. In Figure 1 , a non-significant difference in the cornea thickness and anterior chamber depth could be already demonstrated between the two study cohorts at a preoperative time point $(\mathrm{p}>0.05)$. In FLACS we found a thicker cornea and smaller anterior chamber depth, so we would expect a higher increase in cornea swelling due to the reduced intraocular distance of the applied laser energy. However, we could not find this correlation in our postoperative results. In Figure 1 looking at post surgery results, there was a trend of a raised central cornea thickness in the manual phaco cohort, whereas in the FLACS cohort despite the initial situation (small anterior chamber, thicker cornea) no relevant increase of the central cornea thickness was assessed, which might be due to the reduction of ultrasound energy (31.4\%).

The data were presenting another trend: The peripheral cornea thickness (between $4-8 \mathrm{~mm}$ ) showed an increase in the complete FLACS cohort compared to the manual phaco procedure (Figure 2). This region reflects the area of the laser-cut capsulotomy and the most anterior situated energy level applied during FLACS, thus the results might be correlated to the laser energy used during the capsulotomy. Spliting the cohorts in female and male subjects, the peripheral cornea thickness was significantly increased in the female FLACS cohort (4-8 $\mathrm{mm}, \mathrm{p}<0.05$ ) according to the concentric circles of the Pentacam (Figure 4). However, Niederer et al. [25] found no association between gender and cell density at the level of the basal epithelium ( $\mathrm{p}=0.549)$, stroma $(\mathrm{p}=0.583)$ or endothelium ( $\mathrm{p}=0.691)$, sub-basal nerve fibre density $(\mathrm{p}=0.722)$, central cornea thickness $(\mathrm{p}=0.448)$, corneal astigmatism $(\mathrm{p}=0.973)$ or horizontal corneal diameter $(\mathrm{p}=0.544)$.

In Figure 3 immediately after the femtosecond laser treatment before phacoemulsification, we could not detect an increase in the cornea thickness, especially not centrally located. At 1 day post surgery, however, the cornea thickness was overall increased. It might be assumed that the later rise of the cornea thickness was mainly due to the ultrasound energy, although we are aware of concomitant factors (suction force, duration of cornea swelling, preoperative values).

Additionally, analysing FLACS and manual phacoemulsification with a common range of AC depth distribution (2.5-3.5 mm) no significant differences between the two surgical cohorts could be assessed ( $p>0.05$, Figure 5, Table 1). Future studies need to assess the effect of the laser energy, especially during the capsulotomy before starting the photodisruption process as it was the most anterior situated energy level. Nagy and Yeoh reported about shock waves and bubbles appearing from laser pulses $[2,26]$. One theory was that the bubbles created by the plasma formation could be used as a mirror by the laser rays and thus increasing the potential laser energy level in the anterior part of the eye, also affecting the cornea periphery. We suggested that the application level of the ultrasound energy (more deeply towards the nucleus) and the protection of the endothelial cells due to the viscoelastic leads to a minor clinical impact on the peripheral cornea thickness during a standard cataract surgery [12]. Takács et al. [27] found a significant increase of the central corneal thickness in the phaco group $(607 \pm 91 \mu \mathrm{m})$ compared to the FLACS group (580 $\pm 42 \mu \mathrm{m}$ ) on day 1 , but no significance preoperatively and at 1 week and 1 month. In our study the central cornea thickness did not show a significant difference between both study cohorts, but as mentioned above a similar trend. Takács et al. [27] stated that the femtosecond laser assisted cataract surgery caused less corneal swelling in the early postoperative period and may cause less trauma to corneal endothelial cells than manual phacoemulsification. 
Pre Thickness Corneal

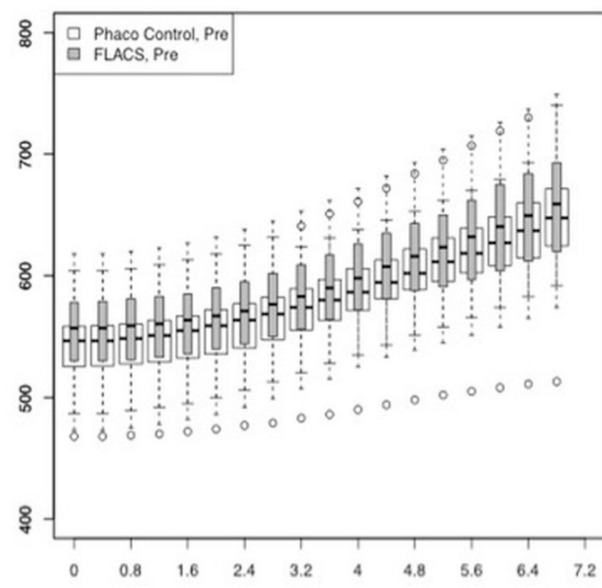

Post Thickness Corneal

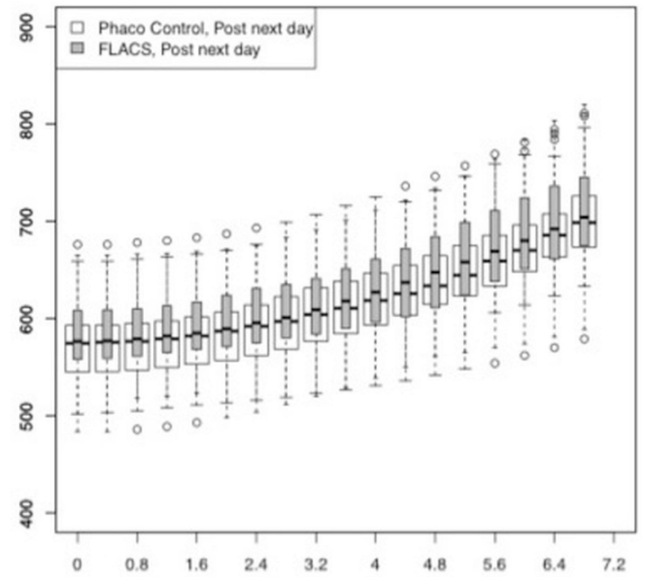

Figure 1. Box Plot analysis of the pre- and postoperative cornea thickness values in the Femtosecond laser assisted cataract surgery (FLACS) and the manual Phacoemulsification cohort according to the concentric rings of the Pentacam.

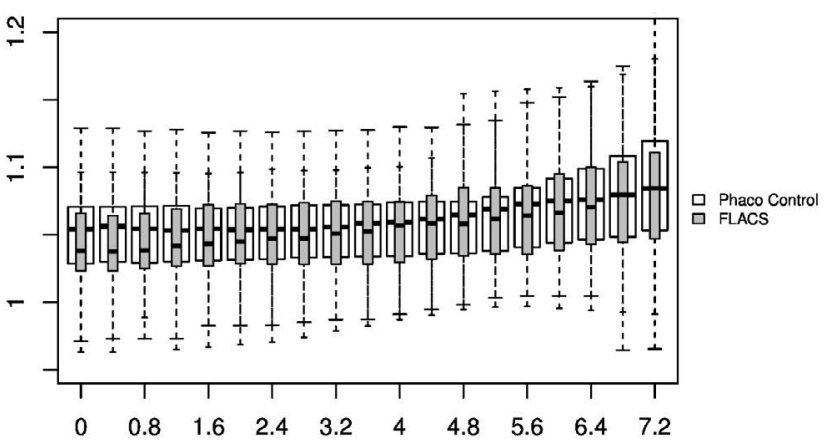

Figure 2. Box Plot analysis of the Ratio 1 day postoperative/ preoperative related to the cornea thickness in the Femtosecond laser assisted cataract surgery (FLACS) and the manual Phacoemulsification cohort according to the concentric rings of the Pentacam.

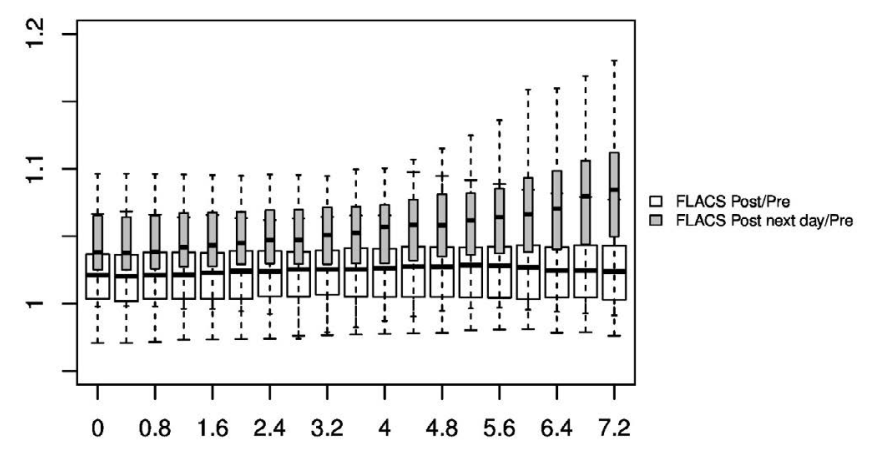

Figure 3. Box Plot analysis of the 2 Ratios post Femtosecond laser treatment/preoperative and 1 day postoperative/ preoperative related to the cornea thickness in the Femtosecond laser assisted cataract surgery (FLACS) cohort according to the concentric rings of the Pentacam.
Considering the endothelial cell count, Kacerovská et al. [28] reported about an average decrease in the number of endothelial cells by $1.1 \%$ in FLACS at 1 day postoperative in contrast to the conventional phaco cohort showing a decrease of $3.8 \%$. In our study cohort we noticed a similar decrease in both surgical procedures; $4.0 \%$ in FLACS and $4.1 \%$ in the manual phaco cohort at 1 day after surgery $(\mathrm{p}>0.05)$. Our values agreed with the first week results by Kacerovská $e t$ al. [28] showing a reduction of endothelial cells by $4.5 \%$ in FLACS and $6.2 \%$ in manual Phaco. The difference between the first day and 1 week results by Kacerovská and this cohort might be due to a different study setting including accuracy of the measuring device, systemic diseases, LOCS criteria and number of patients. Comparative research reported a further reduction of the number of endothelial cells by $5.1 \%$ in FLACS and 9.3\% in conventional phacoemulsification at 1 month after surgery. At 1 year after manual phacoemulsification, $8.5 \%$ cell loss was reported by Takacs et al. [27], no data were shown for FLACS at 1 year.

This study was limited by the following factors; the pressure rise from applanation and the corneal distortion from the application may cause corneal thickening. Variations in the intraocular pressure may have also contributed, although the intraocular pressure was controlled in line with techniques available [29]. Additionally, it is recommended to interpret the impact of different $\mathrm{AC}$ depth cohorts in larger patient cohorts including a notable statistical power [30]. It was reported that the Scheimpflug imaging and optic coherence tomography might underestimate the central cornea thickness in normal eyes compared to the ultrasound pachymetry, with a trend toward thicker measurements in acutely oedematous corneas [31]. Although the central cornea thickness returned to preoperative values at 1 month, the peripheral cornea remained oedematous, possibly because of a correlation with the estimated amount of fluid used and the phacoemulsification time [31]. This impact on the peripheral cornea should be analysed at different follow up visits in future studies. Additionally, the impact on the peripheral cornea should be analysed for different grid patterns. Conrad Hengerer et al. [32] already demonstrated that the use of the femtosecond laser-assisted system with $350 \mu \mathrm{m}$ grid softening led to a statistically significant lower effective phaco time than the $500 \mu \mathrm{m}$ grid. 


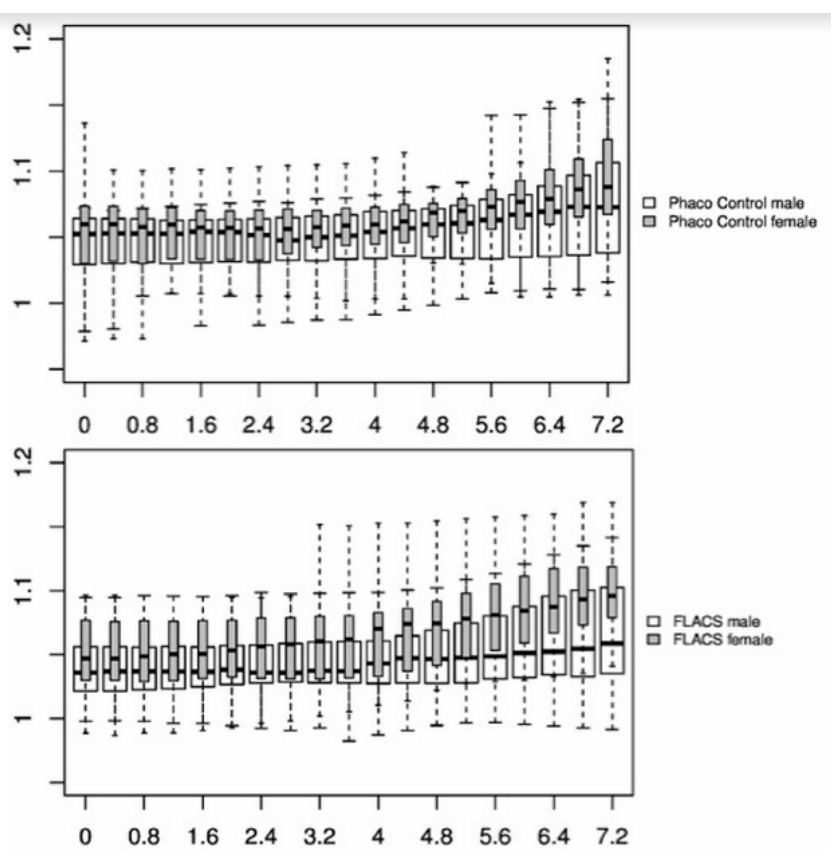

Figure 4. Box Plot analysis of the Ratio 1 day postoperative/ preoperative related to the cornea thickness in female and male subjects of the Femtosecond laser assisted cataract surgery (FLACS) and Phacoemulsification cohort according to the concentric rings of the Pentacam.

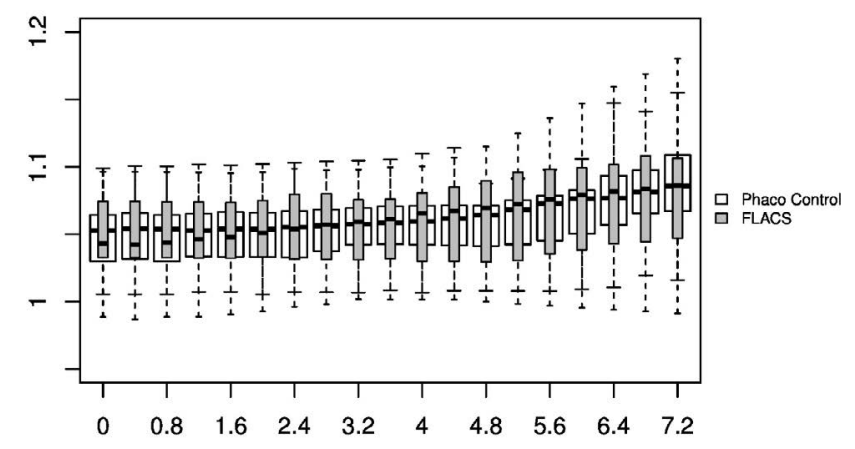

Figure 5. Box Plot analysis of the cornea thickness considering the AC depth subgroup 2.5-3.5 Smm in the Femtosecond laser assisted cataract surgery (FLACS) and the Phacoemulsification cohort according to the concentric rings of the Pentacam.

\section{Conclusion}

In conclusion, the results of this study suggest that the laser energy does not have a relevant clinical impact on the cornea at conventional energy levels. Due to the ultrasound energy reduction there is a trend of less central cornea swelling in the FLACS cohort despite the initial situation (small anterior chamber, thicker cornea) compared to the manual procedure. Future research in laser technology is needed to exactly determine the pathway of the outgoing laser energy.

\section{Declarations}

\section{Competing interests}

The authors declare that they have no competing interests.

\section{Funding}

This research did not receive any specific grant from funding agencies in the public, commercial, or not-for-profit sectors. None of the authors has a financial interest.

\section{Authors' contributions}

ML $\mathrm{P}$ analyzed and interpreted the patient data. TP performed the surgeries and interpreted the data. MP was a major contributor in writing the manuscript. All authors read and approved the final manuscript.

\section{Acknowledgements}

We want to thank Sung-Gon Choe for his statistical expertise.

\section{Meeting}

2016 DOC German Ophthalmology Society, Nürnberg, Germany.

\section{References}

1. Nagy ZZ (2014) New technology update: femtosecond laser in cataract surgery. ClinOphthalmol8: 1157-1167.[Crossref]

2. Nagy ZZ, Mastropasqua L, Knorz MC (2014) The use of femtosecond lasers in cataract surgery: review of the published results with the LenSx system. J Refract Surg30: 730740.[Crossref]

3. Nagy Z, Takacs A, Filkorn T, Sarayba M (2009) Initial clinical evaluation of an intraocular femtosecond laser in cataract surgery. J Refract Surg25: 1053-1060. [Crossref]

4. Aristeidou A, Taniguchi EV2, Tsatsos M3, Muller R4, McAlinden C5, et al. (2015) The evolution of corneal and refractive surgery with the femtosecond laser. Eye Vis (Lond) 2: 12.[Crossref]

5. Nagy ZZ, McAlinden C2 (2015) Femtosecond laser cataract surgery. Eye Vis (Lond) 2: 11.[Crossref]

6. Wang J, Sramek C, Paulus YM, Lavinsky D, Schuele G, et al. (2012) Retinal safety of near-infrared lasers in cataract surgery. J Biomed Opt 17: 95001-95001.[Crossref]

7. Kohnen T, Klaproth O, Ostovic M, Hengerer FH, Mayer WJ (2014) Morphological changes in the edge structures following femtosecond laser capsulotomy with varied patient interfaces and different energy settings. Graefe's Arch ClinExpOphthal252:293-298. [Crossref]

8. González N, Quintana JM2, Bilbao A3, Vidal S4, Fernández de Larrea N5, et al. (2014) Factors affecting cataract surgery complications and their effect on the postoperative outcome. Can J Ophthalmol49: 72-79.[Crossref]

9. Hessemer V, Dick B (1996) [Viscoelastic substances in cataract surgery. Principles and current overview]. KlinMonblAugenheilkd209: 55-61.[Crossref]

10. Craig MT, Olson RJ, Mamalis N, Olson RJ (1990) Air bubble endothelial damage during phacoemulsification in human eye bank eyes: the protective effects of Healon and Viscoat. J Cataract Refract Surg16:597-692. [Crossref]

11. Augustin AJ, Dick HB (2004) Oxidative tissue damage after phacoemulsification: influence of ophthalmic viscosurgical devices. J Cataract Refract Surg30:2. [Crossref]

12. Jurowski P, Gos R, Owczarek G, Gralewicz GZ (2005) Corneal endothelial cells' protection against thermal injury: influence of ophthalmic viscoelastic substances in experimental study on rabbits. Eur J Ophthalmol15:674-679. [Crossref]

13. Beiko GH (2003) Endothelial cell loss after cataract phacoemulsification with Healon5 vs. I-ViscPhaco. Can J Ophthalmol38: 52-56.[Crossref]

14. Brinkmann R, Hüttmann G, Rögener J, Roider J, Birngruber R, et al. (2000) Origin of retinal pigment epithelium cell damage by pulsed laser irradiance in the nanosecond to microsecond time regimen. Lasers Surg Med27: 451-464.[Crossref]

15. Lin CP, Kelly MW (1998) Cavitation and acoustic emission around laser-heated microparticles. Appl Phys Lett72:22.

16. Paltauf G (1999) Photoacoustic cavitation in spherical and cylindrical absorbers. Appl Phys A: Mat Sci68:5. 
17. Hashemi H, Asgari S, Mehravaran S, Emamian MH, Shariati M (2011) The distribution of corneal thickness in a 40- to 64-year-old population of Shahroud, Iran. Cornea30:12. [Crossref]

18. Martin R, Jonuscheit S2, Rio-Cristobal A3, Doughty MJ4 (2015) Repeatability of Pentacam peripheral corneal thickness measurements. Cont Lens Anterior Eye 38: 424429. [Crossref]

19. Buehl W, Stojanac D, Sacu S, Drexler W, Findl O (2006) Comparison of three methods of measuring corneal thickness and anterior chamber depth. Am J Ophthalmol141:1. [Crossref]

20. Magalhaes FP, Costa EF, Cariello AJ, Rodrigues EB, Hofling-Lima AL (2011) Comparative analysis of the nuclear lens opalescence by the Lens Opacities Classification System III with nuclear density values provided by Oculus Pentacam: a cross- section study using Pentacam Nucleus Staging software. Arq Bras Oftalmol74: 110-113. [Crossref]

21. Patrício MS, Almeida AC, Rodrigues MP, Guedes ME, Ferreira TB (2013) Correlation between cataract grading by Scheimpflug imaging and phaco time in phacoemulsification using peristaltic and venturi pumps. Eur J Ophthalmol23: 789792. [Crossref]

22. Sun H, Kurtz RM, Mikula ER, Juhasz T (2011) Temperature increase in porcine cadaver iris during direct illumination by femtosecond laser pulses. $J$ Cataract Refract Surg37: 386-391.[Crossref]

23. Chatoux O, Touboul D, Buestel C, Balcou P, Colin J (2010) [Crystalline lens photodisruption using femtosecond laser: experimental study]. J Fr Ophtalmol33: 472 480.[Crossref]

24. Yagci R, Güler E, Uzun F, Güragaç BF, Acer S, et al. (2015) Assessment of anterior chamber parameters after cataract surgery by Galilei dual Scheimpflug analyzer. Eye Contact Lens 41: 40-43. [Crossref]
25. Niederer RL, Perumal D, Sherwin T, McGhee CN (2007) Age-related differences in the normal human cornea: a laser scanning in vivo confocal microscopy study. $\mathrm{BrJ}$ Ophthalmol91: 1165-1169.[Crossref]

26. Yeoh R (2014) Intraoperative miosis in femtosecond laser-assisted cataract surgery. $J$ Cataract Refract Surg40: 852-853.[Crossref]

27. Takacs AI, Kovacs I, Mihaltz K, Filkorn T, Knorz MC, et al. (2012) Central corneal volume and endothelial cell count following femtosec-ond laser-assisted refractive cataract surgery compared to conventional phacoemulsification. J Refract Surg28: 387 391. [Crossref]

28. Kacerovská J, Kacerovský M, Kadlec R (2013) Development of number of endothelial cells after cataract surgery performed by femtolaser in comparison to conventional phacoemulsification. CeskSlovOftalmol69: 215-218. [Crossref]

29. Trikha S, Turnbull AM, Morris RJ, Anderson DF, Hossain P (2013) The journey to femtosecond laser-assisted cataract surgery: new beginnings or a false dawn? Eye (Lond)27: 461-473.[Crossref]

30. Pahlitzsch M, Torun N, Pahlitzsch ML, Klamann MK, Gonnermann J, et al. (2016) Correlation between anterior chamber characteristics and laser flare photometry immediately after femtosecond laser treatment before phacoemulsification. Eye (Lond) 30: 1110-1117.[Crossref]

31. Wong MM, Shukla AN, Munir WM (2014) Correlation of corneal thickness and volume with intraoperative phacoemulsification parameters using Scheimpflug imaging and optical coherence tomography. J Cataract Refract Surg40: 2067-2075.[Crossref]

32. Conrad-Hengerer I, Hengerer FH, Schultz T, Dick HB (2012) Effect of femtosecond laser fragmentation of the nucleus with different softening grid sizes on effective phaco time in cataract surgery. J Cataract Refract Surg38:1888-1894. [Crossref]

Copyright: (C2017 Pahlitzsch M. This is an open-access article distributed under the terms of the Creative Commons Attribution License, which permits unrestricted use, distribution, and reproduction in any medium, provided the original author and source are credited. 